\title{
The Possibility of Capacity Increase on the Modernised and Electrified Railway Line R201 along the Zaprešić - Zabok Section
}

\author{
Ivica Ljubaj $^{1 *}$, Tomislav Josip Mlinarić ${ }^{1}$, Tomislav Ležaić ${ }^{1}$ and Martin Starčević ${ }^{1}$ \\ ${ }^{1}$ University of Zagreb Faculty of Traffic and Transport Science, 10000 Zagreb, Croatia
}

\begin{abstract}
This paper is focused on the regional railway track line R201 which begins at the Zaprešić railway station (who is a part of the M101 railway line - part of this Mediterranean corridor) and it separates itself from the international Mediterranean TEN-T corridor. In the forthcoming period is planned electrification and modernization of the R201 railway line, so this paper will be focused on capacity calculation as well on the utilization of the new available capacity. There will be made simulation, with the Opentrack program package for railway simulation, of the possibility to equip this line with the ETCS Level 1 and Level 2 safety systems and then it will be made comparation of the results (available capacity) obtained by simulations with the results without having equipped track with these modern safety systems. As the main idea of electrification and modernization of this track is to include her in the suburban passenger system of the city of Zagreb and to transport freight by railway, there will be given some suggestions how to improve capacity utilization
\end{abstract}

\section{Introduction}

The railway line R201, which branches off the international TEN-T corridor, passes through the counties of Zagreb, Krapina - Zagorje, Varaždin, and terminates at Cakovec train station in the Međimurje County. The line is of major significance for regional passenger transport, since commuters in these areas use the railway as their primary method of transport. The railway line is furthermore important as a bypass connection to Slovenia and Austria via Krapina. As modernisation and electrification works are scheduled for this year on the Zaprešić - Zabok section, this paper will analyse and take into consideration only this section of the railway line. The paper will analyse the capacity of the line fitted with the new signal-safety system that will ensure centralised and remote traffic management, as well as the capacity in case the signal-safety system is upgraded with the European Train Control System (ETCS) Levels 1 and 2. Finally, the paper will propose potential improvements of the utilisation of the capacity on the section of the R201 line.

\section{Analysis of the current state and the state after the overhaul}

The R201 railway line is used for regional passenger and freight transport and has a length of $100,7 \mathrm{~km}$. The line has always had outstanding importance for the economic development and growth of the region it passes through. [1]This is a single-track, non-electrified line with trains moving in station distance, with stations fitted with very outdated mechanical or electro-mechanical signal relays. There are 13 stations and 13 stops along the line. The railway line is lowland with an average slope of around 4 $\%$. The technical condition of the upper construction of the railway line is unsatisfactory because the last capital overhaul the line underwent was in 1978, and it used second-hand material. The line is a B2 category line of relatively low axial weight which would amount to 180 $\mathrm{kN} /$ axis per meter and $64 \mathrm{kN} / \mathrm{m}$. The average permitted train speed along the line is $60 \mathrm{~km} / \mathrm{h}$ with a couple of sections that limit the speed to as low as $20 \mathrm{~km} / \mathrm{h}$. The number of trains operating daily on the Zaprešić - Zabok section, the most loaded section, is 27 for passenger and 8 for freight transport. The average journey time on the section is 36 minutes. $[2,3,6,7,9]$

\subsection{Analysis of the Project Status of the Track}

This part of the paper will provide an insight into the future project status of the track upon the completion of the planned overhaul.

As earlier mentioned, the track is of great economic importance to the population of the region it passes through. However, there is a more intensive usage of the track for passenger and freight transport on the Zaprešić - Zabok section, so that part has been selected for the modernisation and electrification, in order to include the

* Corresponding author: ivica.ljubaj@fpz.hr 
section into the suburban passenger transport system of the City of Zagreb. Namely, most of the population using the railway on the section use it to commute to Zagreb and back. Therefore, this will be a single-track, electrified line fitted with an Absolute Permissive Block (APB) system, managed remotely from a central location. The track will be projected so as to allow train speeds of up to $120 \mathrm{~km} / \mathrm{h}$ and basic axial weight of 225 $\mathrm{kN}$ per axis. Moreover, platforms with $160 \mathrm{~m}$ in length will be constructed in all the stations. The minimum track radii will amount to $700 \mathrm{~m}$. [7]

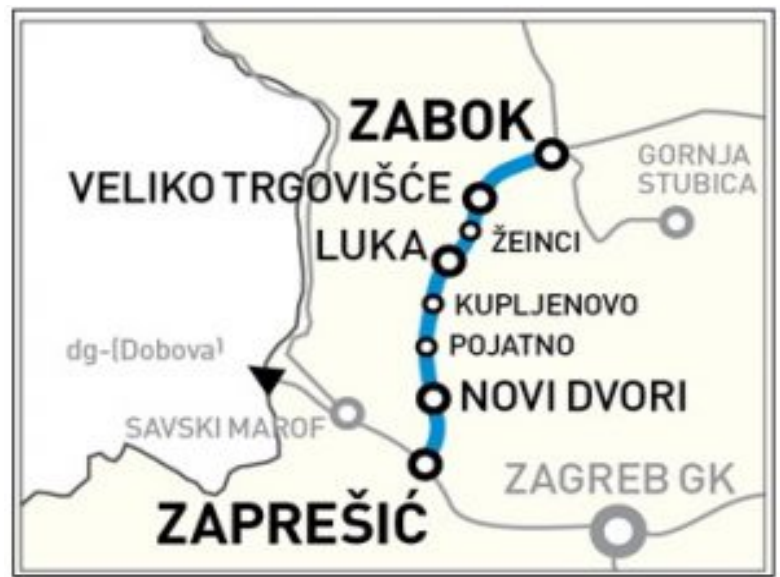

Fig. 1. Railway track R201 Zaprešić - Zabok section [7]

The same data used in the analysis of the future state of the track in this paper will be used to construct a computer model that simulates and calculates the newlyavailable capacity of the track.

\section{European Railway Transport Management System ERTMS}

The modernised and electrified railway line R201 on the Zaprešić - Zabok section is scheduled to be fitted with an INDUSI principle-based safety system and balises AUTOSTOP. These systems have been regulated by enforced Croatian legislation and they prescribe the minimum safety level required for the transport of trains with speeds of up to $160 \mathrm{~km} / \mathrm{h}$. However, the European Union insists on an interoperable railway network, i.e. the TEN-T corridors, and this line should participate in it, as a part of the bypass or access corridor to the Mediterranean corridor. For this to happen, the track needs to be fitted with up-to-date signal and safety relays such as ETCS Levels 1 and 2 and a mobile communication system required by the ECTS Level 2 GSM-R. [4]

\subsection{ETCS Level 0}

ETCS level 0 provides the basic functions for the train driver to supervise the constant (fixed) signals which act as a replacement for the authority/permission to drive. Using signal boxes, all the tasks related to the supervision and control of the track occupancy and for the supervision of the turnouts and relays. On this level, no ERTMS/ETCS equipment is used apart from the eurobalise which is used to transmit a change of the level and all other necessary instructions. Traction vehicles are already fitted with a system for transmitting an electronic telegram using the balise. [4] Figure 2 illustrates the ETCS Level 0.

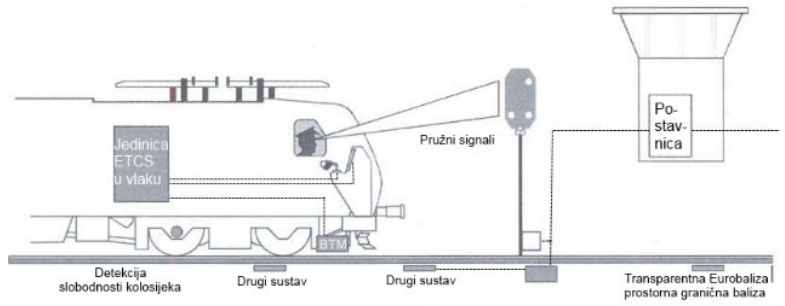

Fig. 2. ETCS Level 0

The main functions provided by the ETCS Level 0 are the supervision of the maximum train speed, maximum train speed when driving in an unfitted area, reading from the eurobalises in order to detect level changes, and other specific instructions. [5]

\subsection{ETCS Level NTC (STM)}

The NTC level is used for controlling ERTMS-/ETCSfitted systems of the national system of driving of trains and supervision of speeds. The information related to train driving generated on the track by the national system is transmitted train-to-train via communication channels of the main national systems.

The track devices fitted along the railway line, level NTC, use a system of transmitting track-to-train from the main national system, which is not a part of the ETCS. For the purposes of changing levels, eurobalises are used.

Similarly, traction vehicles are fitted with the devices used to transmit telegrams using the eurbalises, and a part of the vehicle equipment belongs to the national signal and safety system. [4] Figure 3 illustrates the ETCS level NTC.

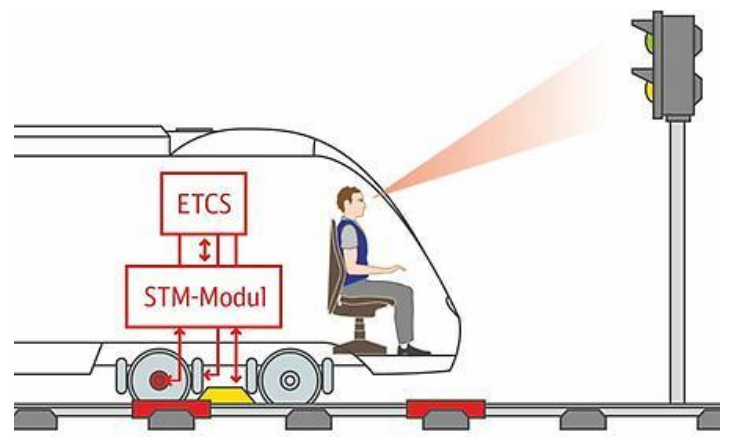

Bsp.: PZB Magnete

Fig. 3. ETCS Level NTC (STM)

The main functions of the ERTMS/ETCS is that there is no supervision of trains since it has been transferred into the national system, and the balises 
would be used to detect the changes in levels and other specific instructions, and managing through the national STM system, if the ETCS devices on a train are linked to the national system and the STM.

\subsection{ETCS Level 1}

The ETCS Level 1 relays data from the track on to the train. Signaling information is obtained via a local Lineside Electronics Unit (LEU) in order to secure the permit to drive. The data is relayed using the balise group, which is electrically connected to the signal or optionally via Euroloop or infill function using the Euroloop or GSM-R. The interlocking remains in charge of the control of the track occupancy, and of the supervision and monitoring of the external equipment. [7]

The track equipment used in this level is eurobalise for the transfer from the track to the train, whereby eurobalises must be able to relay sensitive pieces of information and be used for a semi-continuous infill transmission via Euroloop or Radio infill. Similarly, traction vehicles must be fitted with devices for transmitting the telegram via eurobalise or via radio (if needed).

The main functions of the ETCS on the track are establishing permit to drive based on the underlying signal system for transmitting driving permits and the data on the track features to the train. The signalisation transmits the data on to the DMI (Driver Machine Interface). [4] Figure 4 illustrates the ETCS Level 1.

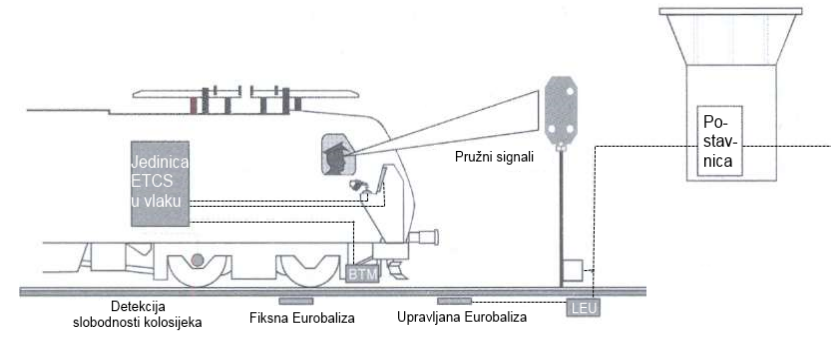

Fig. 4. ETCS Level $1[4]$

ETCS Unit on the train is: Track signals, Detection of the track occupancy, Fixed eurobalise, Operated eurobalise, Interlocking.

\subsection{ETCS Level 2}

ETCS Level 2 ensures a constant supervision in both directions (track - track, train - track) as well as a constant monitoring by the RBC (Radio Block Centre). Outside signals in this level are not required. The communication is transmitted via GSM-R. The interlocking is responsible for controlling track occupancy, turnouts and signals, and the information on the scheduled routes are transmitted to the RBC.

The required track equipment on this level is a radio block centre (RBC), and EuroRadio for the two-way communication between train and track. Eurobalises are used mainly for transmitting location data. Trains are fitted with devices for transmitting information via eurobalises and euroradio. [4] Figure 5 is a schematic

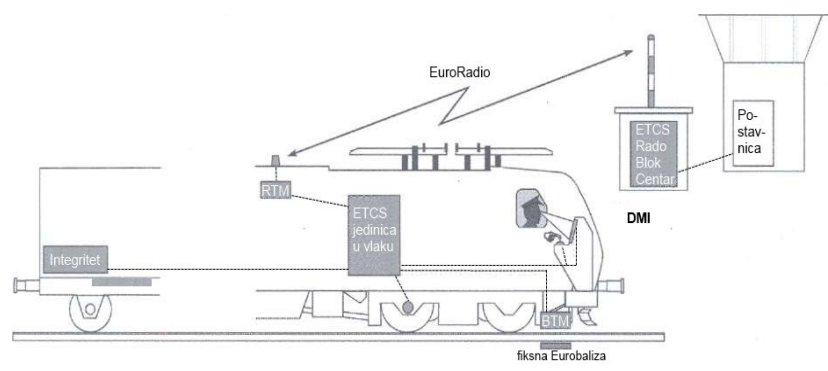

representation of the ETCS Level 2.

Fig.5. ETCS Level 2 [4]

The main functions of ERTMS/ETCS on the track are familiarity with the equipment of every train with ETMS/ETCS and operating in the system of ERTMS/ETCS within the RBA (Radio Block Area) using its ERTMS/ETCS identity, monitoring the location of every train controlled by ERTMS/ETCS within the RBA, determining permits for driving the train in accordance with the basic signal system for each train, and handing off the supervision of trains, transferring driving permits and track descriptions, and handing off the supervision of trains between different RBCs on the RBC-RBC borders.

The main functions of the ERTMS/ETCS onboard a train are reading of the eurobalises and transmitting the position of the train with regard to the detected balise to the $\mathrm{RBC}$. The train receives permission to drive and track description via Euroradio. Furthermore, the most restrictive value of different train speeds is selected and permitted on every location in front of the train, calculating the dynamic profile of the speed taking into consideration the characteristics of the drive/braking of the train which are available onboard, as well as the data on the track, comparing the speed of the train with the permitted speed and issuing instructions for activating brakes if required, and transmitting signals to the train driver on to the DMI. [4]

This part of the paper will not analyse ETCS Level 3, since the level is still in its experimental phase and not in commercial use.

\section{Simulation and the obtained capacity results}

This railway line is seen as extremely significant for passenger transport due to the fact that there are plans include it in the suburban transport system of the City of Zagreb. [5] It is expected that, after the liberalisation of the railway passenger transport market, i.e. opening thereof, railway operators will show interest in passenger transport on this section. In order to ensure access to the market, the train fleet must consist of modern and economically efficient trains. In that sense, trains will surely be fitted with modern signal and safety systems (ETCS equipment) which will then ensure interoperability, that is, operating on the railway tracks owned by other railway undertakings. This paper will, 
therefore, analyse, simulate, and outline potential solutions for the utilisation of the maximum capacity of the track with regard to the signal and safety equipment, i.e. ATP - Automatic Train Protection.

It has earlier been established that the track capacity on the Zaprešić - Zabok section amounts to 57 trains, and that, based on the existing timetable, the utilisation of the capacity is $66 \%$. [5]

After the estimation of the modernisation, maximum utilised capacity was calculated and it amounted to 87 trains, the latter capacity is a 50 percent increase of the original capacity after the modernisation. Figure 6 show this new available capacity. This capacity is available when taking into consideration the newly-installed signal and safety system (APB) and remote train transport management located in Zabok station. [8,9]

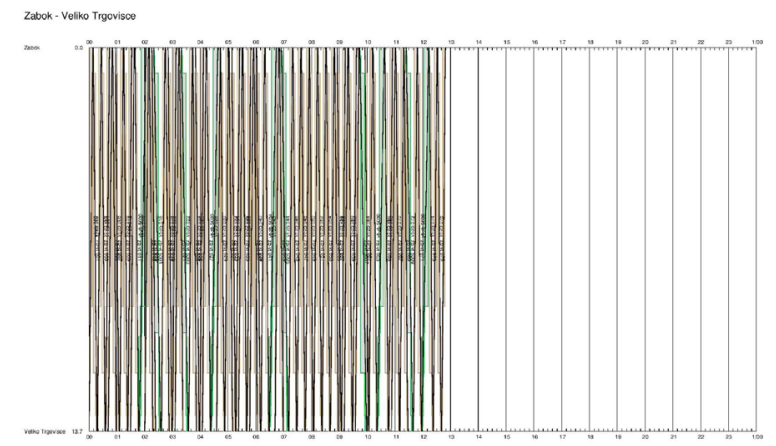

Fig.6. Compressed timetable for maximum capacity calculation

Upon the construction of the model and the change of the signal and safety system by means of modernising the section, the track capacity was determined at 87 trains. Evidently, the latter capacity is a 0 percent increase of the original capacity after the modernisation, which is why the investments in the modernisation of the track become substantially more expensive. [9-11]

ETCS Level 2 was also simulated in the model, whereby the reconstructed section was upgraded with a signal and safety equipment of the corresponding level. The calculation revealed the track capacity of 87 trains. Therefore, the obtained capacity is 0 percent higher than the original one after the modernisation, which further increases the cost of the investment, which is even greater than the investment in ETCS Level 1.

\section{Conclusion}

The railway line R201 is of great importance for the entire region it passes through, and it is essential that it be modernised. By modernising the Zaprešić - Zabok section, the line can be included into the suburban transport system of the City of Zagreb, thereby making it easier for residents to commute to Zagreb and back. The project documentation reveals that the track is scheduled to be modernised and electrified in order to increase its axial weight load so that the commercial speed may increase from 60 to $120 \mathrm{~km} / \mathrm{h}$. This increase would shorten journey time by 5-10 minutes, which may not be a great improvement, but will ensure the provision of a higher quality of service in terms of more frequent departures, more modern, faster and economically efficient motorised trains, as well as the possibility of private operators offering transport service. At the same time, the railway undertaking will benefit from higher profits coming from infrastructure fees, and the fact that the railway line will become more appealing to freight operators, due to the increase in axial load, as trains will be able to load more cargo.

This paper has shown that the upgrade of the modernised and electrified track by means of a signal safety system would not justify the investment since the capacity would largely remain the same. In fact, greater benefit would be ensured by fitting STM systems onboard trains which could then, using modern signal and safety systems, operate using the national ATP system, and ETCS as well.

\section{References}

1. D. Badanjak, B. Bogović, V. Jenić, Organizacija željezničkog prometa (2006)

2. I. Ljubaj, M. Petrović, T.J. Mlinarić, Analysis of Public Transport Offer in Krapina-Zagorje County and Proposal of Integration Point // Horizons of Railway Transport (2017)

3. M. Mikulčić, I. Ljubaj, M. Petrović, Analysing the Railway Passenger Train Operation Using a Simulation Model // Horizons of Railway Transport (2017)

4. P. Steinly, ETCS for engineers $1^{\text {st }}$ edition (2011)

5. Fakultet prometnih znanosti \& DB Engineering \& Consulting GmbH, Studija uvođenja europskog sustava upravljanja željezničkim prometom (ERTMS) (2016)

6. J. Klimková, J. Čamaj, J. Gašparík. Transport means 2016: proceedings of the 20th international scientific conference. 891-896. (2016)

7. HŽ Infrastruktura d.o.o., Izvječće o mreži 2018, (2018)

8. B. Abramović, J. Gašparík, Jozef, V. Zitrický. Tehnički Vjesnik. 25, 4. 1190-1195. (2018),

9. HŽ Infrastruktura d.o.o., Projektna dokumentacija projekta: Modernizacija $i$ elektrifikacija pruge Zaprešić - Zabok (2016)

10. HŽ Infrastruktura d.o.o., Uputa za utvrđivanje pružnih i kolodvorskih kapaciteta - Uputa HŽI-70 (2014)

11. HŽ Infrastruktura d.o.o., Materijali voznog reda 2017/2018 (2017) 